\title{
Parametric Study of Plasma and Metallic Antenna
}

\author{
P. Kumar' ${ }^{1}$ R. Kumar ${ }^{2 *}$ \\ ${ }^{1}$ Dept. Physics, Dr. Harisingh Gour Central University, Sagar, India \\ ${ }^{2}$ Dept. Physics, Banaras Hindu University, Varanasi, India \\ *Corresponding Author: rajneeshipr@gmail.com, Tel.: +91-91797-02674
}

Available online at: www.isroset.org

Accepted: 24/Dec/2017, Online: 30/Aug/2018

\begin{abstract}
This paper is intended to the study of antenna parameters of plasma antennas to help the optimization of plasma antenna dimensions (radius and length). To accomplish this, three configurations of plasma antenna are simulated. The observations are taken on variations in the antenna parameters with the different radius and length of the plasma column. Additionally, to acquire similarity with metallic antenna, three models of metallic (copper) antenna are also be simulated with same configurations as plasma antennas. It is a comprehensive study of antenna parameters of the different configurations of plasma antennas and comparative study between the metallic and plasma antennas. Results suggest, the plasma antenna and metallic antenna are showing similar radiation patterns for each types of modals and at all the resonance frequencies, however the resonance frequencies and gain are different for different configurations of plasma antennas. The plasma antenna has become very useful applications in the field of communication and this paper provide important information about the antenna parameters of plasma antenna, along with the comparative study of antenna parameters with the metallic antenna. The paper deals with the different resonance frequencies of plasma antenna and hence reports about the re-tunability of plasma antenna as well.
\end{abstract}

Keywords - Plasma Antenna, Antenna Parameters, Resonance Frequency, Antenna and communication

\section{INTRODUCTION}

The plasma based technologies are in the age of evolution, researchers are continuously working on the plasma based industrial applications. Among the various applications of plasma based technology the most interesting one is the plasma antenna. Actually plasma antenna is an antenna in which metallic counterpart of an antenna is replaced by the plasma, in order to achieve many attractive characteristics that makes plasma antenna more advantageous than conventional metallic antenna [1]. The conventional antennas are made up of metal and metals are solid in nature and hence they have a particular shape and size. To change the configuration of a metallic antenna, we need to change the whole antenna mechanically. But in the recent time these limitations make metallic antenna uncomfortable in many fields where space and time is limited. As well as nowadays people needed multipurpose device to reduce the need of several devices. Based on the above discussed difficulties the plasma antenna may be a suitable option for the metallic antenna because it has following characteristics. The plasma antenna is constructed by a dielectric tube, which is filled with a noble gas. The gas is ionized to convert into the plasma and then this column of plasma is used as an antenna [2]. Since plasma antenna is made up of gas and dielectric tube hence it is light weighted than the metallic antenna of same configuration. The existence of plasma inside the dielectric column is depends on the ionizing potential, so it is possible to control appearance of plasma antenna by the electric switches [3]. The length of plasma column is directly proportional to the applied potential and hence length of plasma antenna can be controlled by the amount applied potential [4]. A monopole plasma antenna can work similar as a metallic antenna of copper [5]. The striations formed in a plasma column by changing some operating parameters, can be transformed a plasma antenna into a re-configured plasma antenna or in an array antenna [6]. A smart plasma antenna can steer the radiation pattern in different directions electronically [7]. On the basis of above advantages plasma antenna now it is becomes an intrusting topic for research.

Most of the earlier works on plasma antenna are deals with experimental approach and short discussion about the theory of plasma antenna. This paper is discuses basic theory about plasma antenna, plasma parameters (i.e. plasma frequency, plasma conductivity, plasma density) with simulating the plasma antenna on HFSS software and find antenna parameters of it, to understand performance of plasma antenna in comparison with the metallic antenna. 
In this paper, we will present the principal theory on plasma with the corresponding equations in section II. Then the design of plasma antenna will be introduced in section III. Section IV will presents result of different plasma antennas. In section $\mathrm{V}$ we will discuss about the result. At the last, summary of the paper will present in section VI.

\section{Theory and Plasma Parameters}

As plasma is conglomeration of charged and neutral particles, it has conductivity. This conductivity is small compared to the metallic conductivity but sufficient to use plasma for the purpose of antenna. In plasma the ions are much heavier than the electrons so they only provide a positive background and not much contributed for the conductivity for that reason the conductivity of plasma is mainly depends on the number of electrons. The conductivity of the weakly ionized plasma can be calculated by the following formula [8].

$$
\sigma=e^{2} N_{e} / m_{e} v_{m}
$$

Here $e$ is the electronic charge, $N_{e}$ is the electron density, $m_{e}$ is the mass of electron and $v_{m}$ is the collision frequency.

Plasma in terms of electromagnetic properties is a nonhomogeneous, non-linear and dispersive environment. Permeability $(\mu)$, conductivity $(\sigma)$ and permittivity $(\varepsilon)$ in plasma can be varied in terms of plasma frequency and other parameter along with makes plasma is a special environment. As a result, for any frequency of the incident wave and in any density of ionization, one particular response occurs. Radiated electromagnetic waves on plasma will absorb, scatter or pass through. We can choose to absorb, scatter or pass through with changing the basic parameters like electron density and collision frequency. The relative permittivity of plasma is defined by [8].

$$
\begin{aligned}
& \varepsilon_{r}=\varepsilon_{r}^{\prime}-j \varepsilon_{r}^{\prime \prime} \\
& \varepsilon_{r}=1-\left\{\omega_{p}^{2} / \omega\left(\omega-j v_{m}\right)\right\}
\end{aligned}
$$

where $\omega_{\mathrm{p}}$ is plasma frequency and $\omega$ is operating frequency. One must distinguish the difference between the plasma frequency and the operating frequency of the plasma antenna. The plasma frequency is a measure of the amount of ionization in the plasma and the operating frequency of the plasma antenna is the same as the operating frequency of a metal antenna. Plasma frequency is equal to [7]:

$$
\omega_{p}=\sqrt{N_{e} e^{2} / \varepsilon_{0} m_{e}}
$$

Assuming a time harmonic wave with an $e^{i \omega t}$ time dependence is propagating in the $+\mathrm{z}$ direction has the form

$$
E(z)=k E_{0} \mathrm{e}^{-\gamma z}
$$

For the special case of negligible collisions, $\vartheta_{m}=0$, the corresponding propagation constant is

$$
\gamma=i k_{0} \sqrt{\omega_{p}^{2} / \omega^{2}}
$$

The behavior of wave into plasma depends on propagation constant which is different in three cases. When $\omega>\omega_{p e}$ the $\gamma$ is imaginary and wave will propagate wave, for $\omega<\omega_{p e}$ then $\gamma$ is real and wave is an evanescent wave and for $\omega=\omega_{p e}$ then $\gamma=0$ and this value of $\omega$ is called the critical frequency $\omega_{c}$, which defines the boundary between propagation and attenuation of the EM wave. Plasma behaves as a dielectric medium with negative dielectric constant for frequencies above the plasma frequency. In the case, plasma transmits electromagnetic waves with the dispersion relation

$$
\omega^{2}=\omega_{p e}^{2}+\gamma^{2} c^{2}
$$

Where $c$ is the velocity of light. For frequencies below the plasma frequency, plasma cannot transmit EM waves. At plasma-dielectric interface, surface wave propagates along the interface.

\section{Simulations}

To design a plasma antenna on High Frequency Structure Simulator (HFSS) software, it requires some plasma parameters like plasma conductivity, plasma density, and plasma permittivity. These parameters of plasma are calculated theoretically by the formulas given in section 2 . These parameters are as follows, plasma electron density is chosen to be $n_{e} \sim 10^{16} \mathrm{~m}^{-3}$ and the collision frequency $v_{m} \sim$ $4 \times 10^{8} \mathrm{~Hz}$ both are calculated in [5]. Hence from (1) the plasma conductivity is $\sigma=22.5$ simens $/ \mathrm{m}^{3}$ and from (4) the plasma frequency is $\omega_{p}=30 \times 10^{6} \mathrm{~Hz}$.

\section{A. Design of Antennas}

Based on HFSS, Model of plasma antenna can be designed with assign values. In this paper we simulate three different configuration of plasma antenna without changing any plasma parameter. The two among them are same in length $120 \mathrm{~cm}$ but different in radius i.e. $1.8 \mathrm{~cm}$ and $0.8 \mathrm{~cm}$, while two among them are same in radius $1.8 \mathrm{~cm}$ but different in length i.e. $120 \mathrm{~cm}$ and $60 \mathrm{~cm}$. In each configuration, a glass tube is designed of required length and radius and tube filled with the plasma medium of parameters are mentioned above. In the whole tube plasma density is taken uniformed. A port as a source is assigned at the center of the glass tube. An air volume object is designed as a radiation boundary infinitely far from the antenna. 
To compare the plasma antenna parameters we also designed three metallic (Copper) antenna of same configuration as plasma antennas. The simulated models for plasma antenna and metallic antenna are shown in the Figure 1 and Figure 2, respectively.

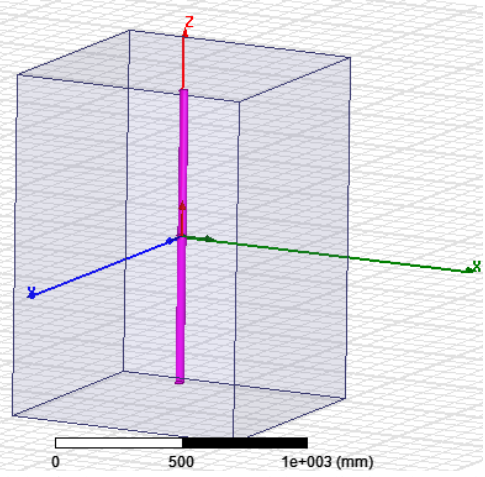

Figure 1. Model of plasma antenna with radiation boundary

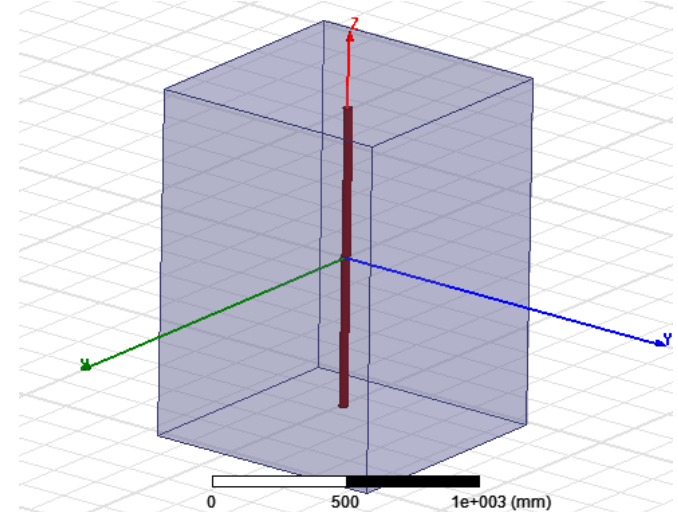

Figure 2. Model of metallic antenna with radiation boundary

\section{RESUlts}

\section{A. S-parameter}

The return loss of an antenna is measure of how much power is reflected by the antenna towards the source when its works like a transmitter and towards atmosphere when it is a receiver. It is due to impedance mismatch between antenna and transmission line. The higher values of return loss are needed to be a good antenna because higher the return loss represents lower the mismatch. S-parameters describe the input-output relationship between ports (or terminals) in an electrical system. The s11 parameter represents how much power is reflected from antenna in certain frequency. Any frequency at which s11 has minimum value is called resonance frequency of the antenna and at that frequency antenna will transmit maximum power. In this paper, we find $S$-parameter for all the configuration of plasma antennas over the frequency range from $1 \mathrm{MHz}$ to $1 \mathrm{GHz}$.

Figure 3 and Figure 4 show the S-parameter for plasma antenna and metallic antenna of $1.8 \mathrm{~cm}$ in radius and $120 \mathrm{~cm}$ in length, respectively. The resonance frequencies for metallic antenna of this configuration of the antenna are 131 $\mathrm{MHz}, 363 \mathrm{MHz}, 590 \mathrm{MHz}$ and $840 \mathrm{MHz}$ and the return losses corresponding to these resonance frequencies are -10.0 $\mathrm{dB},-9.4 \mathrm{~dB},-8.4 \mathrm{~dB}$ and $-8.0 \mathrm{~dB}$, respectively. The resonance frequencies for plasma antenna of this configuration of the antenna are $171 \mathrm{MHz}, 348 \mathrm{MHz}, 595$ $\mathrm{MHz}$ and $840 \mathrm{MHz}$ and the return losses corresponding to these resonance frequencies are $-8.0 \mathrm{~dB},-9.3 \mathrm{~dB},-8.4 \mathrm{~dB}$ and $-7.7 \mathrm{~dB}$, respectively.

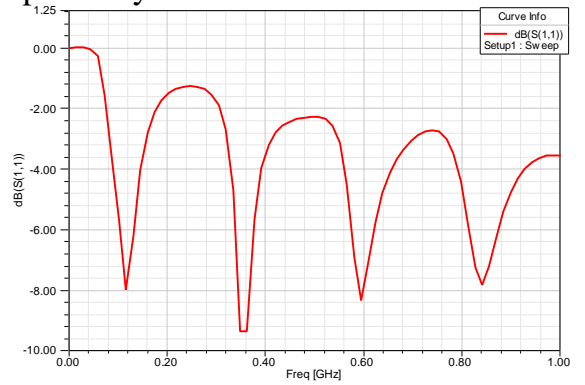

Figure 3. S-Parameter plasma antennas of diameter of $1.8 \mathrm{~cm}$ and length 120

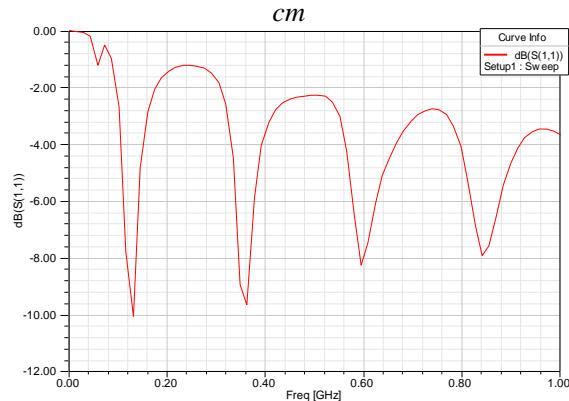

Figure 4. S-Parameter metallic antennas of diameter of $1.8 \mathrm{~cm}$ and length $120 \mathrm{~cm}$

Figure 5 and Figure 6 show the S-parameter for plasma antenna and metallic antenna of $0.8 \mathrm{~cm}$ in radius and $120 \mathrm{~cm}$ in length, respectively. The resonance frequencies for metallic antenna of this configuration of the antenna are 115 $\mathrm{MHz}, 380 \mathrm{MHz}, 630 \mathrm{MHz}$ and $884 \mathrm{MHz}$ and the return losses corresponding to these resonance frequencies are -8.4 $\mathrm{dB},-10.4 \mathrm{~dB},-8.4 \mathrm{~dB}$ and $-7.8 \mathrm{~dB}$, respectively. The resonance frequencies for plasma antenna of this configuration of the antenna are $112 \mathrm{MHz}, 360 \mathrm{MHz}, 630$ $\mathrm{MHz}$ and $880 \mathrm{MHz}$ and the return losses corresponding to these resonance frequencies are $-11.2 \mathrm{~dB},-9.6 \mathrm{~dB},-8.4 \mathrm{~dB}$ and $-8.6 \mathrm{~dB}$, respectively.

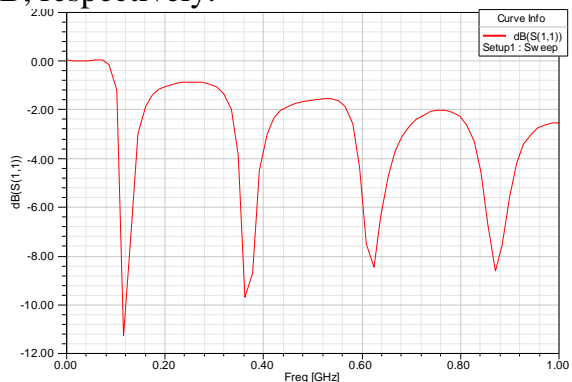

Figure 5. S-Parameter plasma antennas of diameter of $0.8 \mathrm{~cm}$ and length 120 $\mathrm{cm}$ 


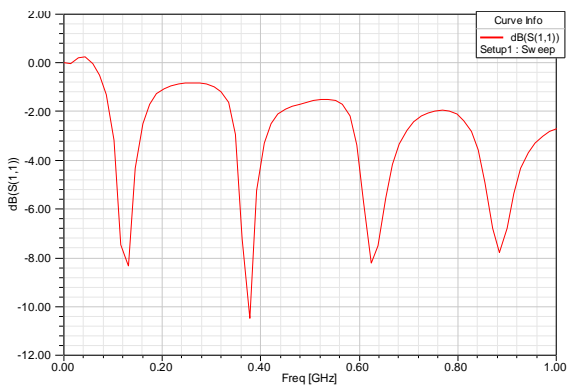

Figure 6. S-Parameter metallic antennas of diameter of $0.8 \mathrm{~cm}$ and length $120 \mathrm{~cm}$

Figure 7 and Figure 8 show the S-parameter for plasma antenna and metallic antenna of $1.8 \mathrm{~cm}$ in radius and $60 \mathrm{~cm}$ in length, respectively. The resonance frequencies for metallic antenna of this configuration of the antenna are 220 $\mathrm{MHz}$ and $700 \mathrm{MHz}$ and the return losses corresponding to these resonance frequencies are $-17.2 \mathrm{~dB}$ and $-9.0 \mathrm{~dB}$, respectively. The resonance frequencies for plasma antenna of this configuration of the antenna are $220 \mathrm{MHz}$ and 700 $\mathrm{MHz}$ and the return losses corresponding to these resonance frequencies are $-17.2 \mathrm{~dB}$ and $-9.0 \mathrm{~dB}$, respectively.

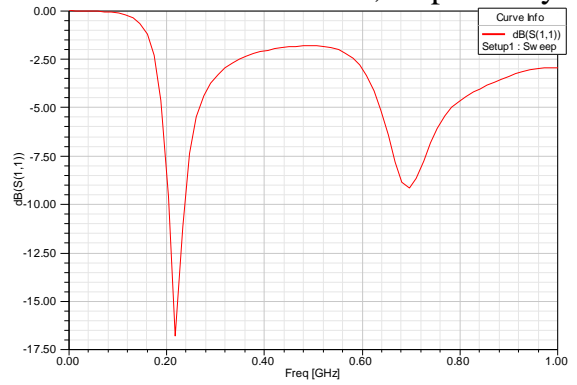

Figure 7. S-Parameter plasma antennas of diameter of $1.8 \mathrm{~cm}$ and length 60 $\mathrm{cm}$

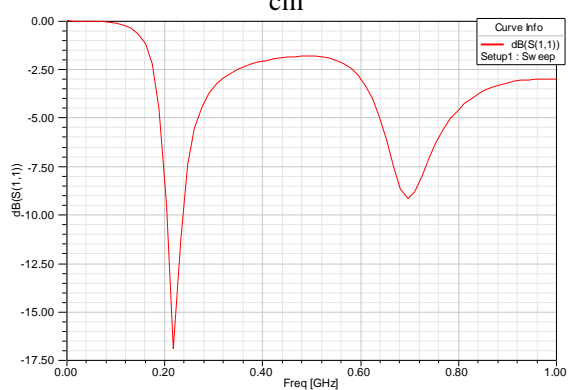

Figure 8. S-Parameter metallic antennas of diameter of $1.8 \mathrm{~cm}$ and length 60 $\mathrm{cm}$

\section{B. Radiation Patterns}

The radiation pattern is an important property of the antenna. The power received at a point by a receiving antenna is a function of the position of the receiving antenna with respect to the transmitting antenna. At a constant radius from transmitting antenna graph of the received power is called the power pattern which is a spatial pattern. The special pattern of the electro-magnetic field is called field pattern. A cross section of this field pattern in any particular plane is called "radiation pattern" in that plane. In this paper radiation pattern for gain of antenna is observed. Gain is an impotent parameter for antenna which is useful measure describing the performance of an antenna although the gain of the antenna is closely related to directivity. The only difference between gain and directivity is that directivity is based entirely on the shape of the radiated power pattern but gain taken into account antenna efficiency as well as its directional capabilities. Higher gain in one direction means lower gain in other directions. High gain antennas allow longer range in one direction, but need to be pointed accurately. Low gain antennas have lower range, but can receive signals from wider span of directions [9].

Radiation patterns are obtained for all configurations of plasma antennas and metallic antennas at all the observed resonance frequencies. The radiation patterns are found in both plane the azimuthal and elevation. It has been observed that radiation pattern in azimuthal plane for all the configurations are symmetric around the axis but elevation pattern are different. Therefore only elevation patterns are shown in results.

Radiation patterns for plasma antenna and metallic antenna of length $120 \mathrm{~cm}$ and radius $1.8 \mathrm{~cm}$ are shown in the Figure 9 and Figure 10, respectively. Figure 9(a), Figure 9(b), Figure 9(c) and Figure 9(d) are radiation patterns for plasma antenna of radius $1.8 \mathrm{~cm}$ and length $120 \mathrm{~cm}$ at the resonance frequency171 MHz, $348 \mathrm{MHz}, 595 \mathrm{MHz}$ and $840 \mathrm{MHz}$, respectively. Figure 10(a), Figure 10(b), Figure 10(c) and Figure $10(d)$ are radiation patterns for metallic antenna of radius $1.8 \mathrm{~cm}$ and length $120 \mathrm{~cm}$ at the resonance $131 \mathrm{MHz}$, $363 \mathrm{MHz}, 590 \mathrm{MHz}$ and $840 \mathrm{MHz}$, respectively.
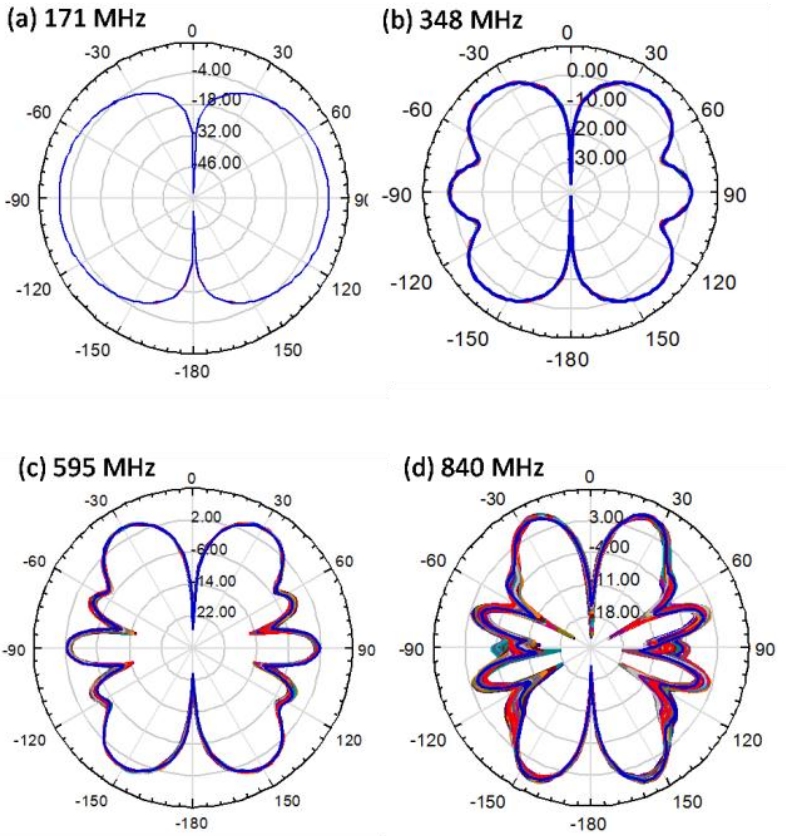

Figure 9. Radiation patterns for plasma antennas of diameter of $1.8 \mathrm{~cm}$ and length $120 \mathrm{~cm}$ 
(a) $131 \mathrm{MHz}$
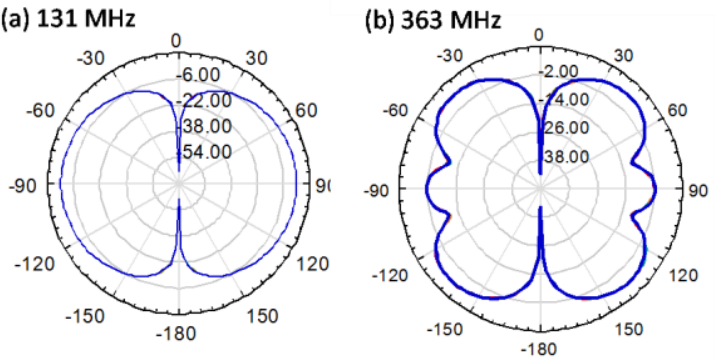

(c) $590 \mathrm{MHz} \quad 0$
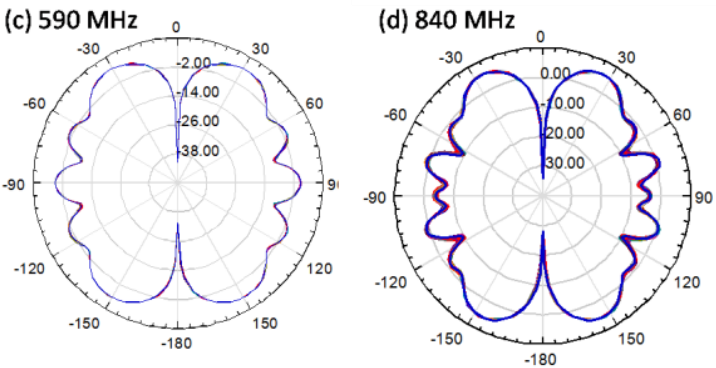

Figure 10. Radiation patterns for metallic antennas of diameter of $1.8 \mathrm{~cm}$ and length $120 \mathrm{~cm}$

Radiation patterns for plasma antenna and metallic antenna of length $120 \mathrm{~cm}$ and radius $0.8 \mathrm{~cm}$ are shown in the Figure 11 and Figure 12, respectively. Figure 11(a), Figure 11(b), Figure 11(c) and Figure 11(d) are radiation patterns for plasma antenna of radius $0.8 \mathrm{~cm}$ and length $120 \mathrm{~cm}$ at the resonance frequency $112 \mathrm{MHz}, 360 \mathrm{MHz}, 630 \mathrm{MHz}$ and 880 $\mathrm{MHz}$, respectively. Figure 12(a), Figure 12(b), Figure 12(c) and Figure $12(\mathrm{~d})$ are radiation patterns for metallic antenna of radius $0.8 \mathrm{~cm}$ and length $120 \mathrm{~cm}$ at the resonance 115 $\mathrm{MHz}, 380 \mathrm{MHz}, 630 \mathrm{MHz}$ and $884 \mathrm{MHz}$, respectively.
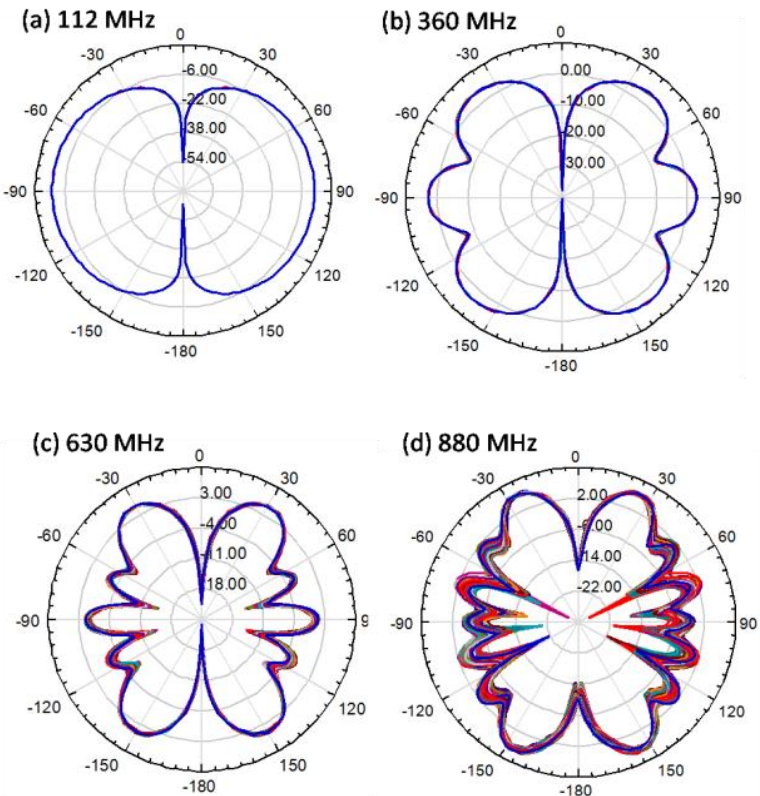

Figure 11. Radiation patterns for plasma antennas of diameter of $0.8 \mathrm{~cm}$ and length $120 \mathrm{~cm}$
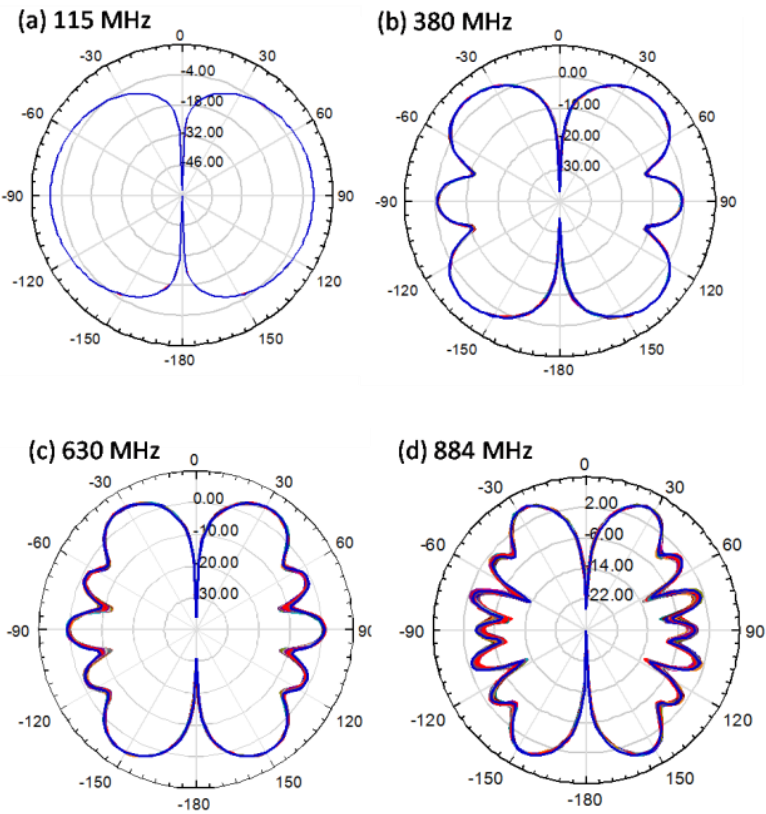

Figure 12. Radiation patterns for metallic antennas of diameter of $0.8 \mathrm{~cm}$ and length $120 \mathrm{~cm}$

Radiation patterns for plasma antenna and metallic antenna of length $60 \mathrm{~cm}$ and radius $1.8 \mathrm{~cm}$ are shown in the Figure 13 and Figure 14, respectively. Figure 13(a) and Figure 13(b) are radiation patterns for plasma antenna of radius $1.8 \mathrm{~cm}$ and length $60 \mathrm{~cm}$ at the resonance frequency $220 \mathrm{MHz}$ and $700 \mathrm{MHz}$, respectively. Figure 14(a) and Figure 14(b) are radiation patterns for metallic antenna of radius $1.8 \mathrm{~cm}$ and length $60 \mathrm{~cm}$ at the resonance $220 \mathrm{MHz}$ and $700 \mathrm{MHz}$, respectively.
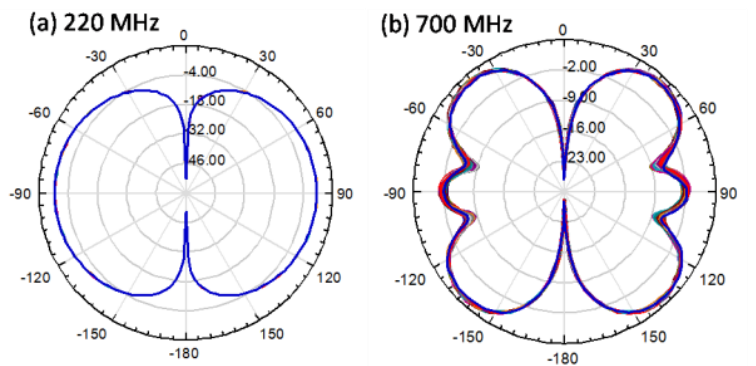

Figure 13. Radiation patterns for plasma antennas of diameter of $1.8 \mathrm{~cm}$ and length $60 \mathrm{~cm}$
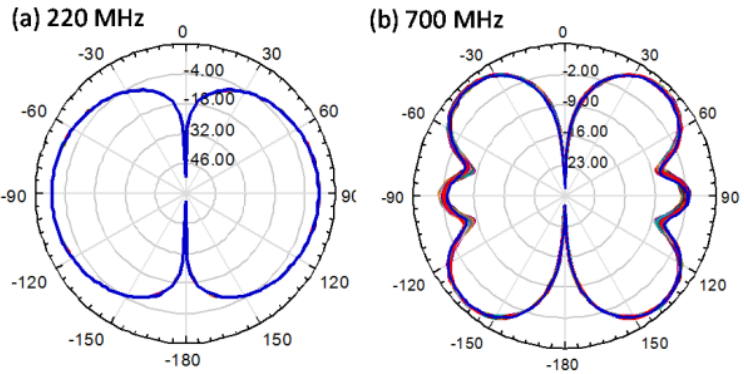

Figure 14. Radiation patterns for metallic antennas of diameter of $1.8 \mathrm{~cm}$ and length $60 \mathrm{~cm}$ 


\section{Discussion}

For the plasma antenna and metallic antenna of radius $1.8 \mathrm{~cm}$ and length $120 \mathrm{~cm}$, gains corresponding to the resonance frequencies are shown in the Table 1. From the Table 1 it is clear that for both the antennas four resonance frequencies are obtained in the range of $1 \mathrm{MHz}$ to $1 \mathrm{GHz}$. Theses resonance frequencies are nearly same but the gain corresponding to them are different for both the antennas. Furthermore from radiation patterns for these antennas it is observed that radiation patterns are Omni-directional at the lower frequencies (117 MHz and $131 \mathrm{MHz}$ ) while both the antennas get directive towards the higher frequencies.

Table 1. Resonance frequency and corresponding Gain for configuration of $1.8 \mathrm{~cm}$ and length $120 \mathrm{~cm}$

\begin{tabular}{|c|c|c|c|c|}
\hline \multirow{2}{*}{ S. No. } & \multicolumn{2}{|c|}{ Plasma antenna } & \multicolumn{2}{c|}{ Metallic antenna } \\
\cline { 2 - 5 } & $\begin{array}{c}\text { Resonance } \\
\text { frequency } \\
(\mathrm{MHz})\end{array}$ & $\begin{array}{c}\text { Gain } \\
(\mathrm{dB})\end{array}$ & $\begin{array}{c}\text { Resonance } \\
\text { frequency } \\
(\mathrm{MHz})\end{array}$ & $\begin{array}{c}\text { Gain } \\
(\mathrm{dB})\end{array}$ \\
\hline 1 & 117 & 1.14 & 131 & 1.78 \\
\hline 2 & 348 & 3.88 & 363 & 4.28 \\
\hline 3 & 595 & 5.08 & 590 & 4.52 \\
\hline 4 & 840 & 7.22 & 840 & 5.79 \\
\hline
\end{tabular}

For the plasma antenna and metallic antenna of radius $0.8 \mathrm{~cm}$ and length $120 \mathrm{~cm}$, gains corresponding to the resonance frequencies are shown in the Table 2. Similarly from the Table 2 it is clear that for both the antennas four resonance frequencies are obtained in the range of $1 \mathrm{MHz}$ to $1 \mathrm{GHz}$. Theses resonance frequencies are nearly same but the gain corresponding to them are different for both the antennas. Furthermore from radiation patterns for these antennas it is observed that radiation patterns are Omni-directional at the lower frequencies $(112 \mathrm{MHz}$ and $115 \mathrm{MHz}$ ) while both the antennas get directive towards the higher frequencies.

Table 2. Resonance frequency and corresponding Gain for configuration of $0.8 \mathrm{~cm}$ and length $120 \mathrm{~cm}$

\begin{tabular}{|c|c|c|c|c|}
\hline \multirow{2}{*}{ S. No. } & \multicolumn{2}{|c|}{ Plasma antenna } & \multicolumn{2}{c|}{ Metallic antenna } \\
\cline { 2 - 5 } & $\begin{array}{c}\text { Resonance } \\
\text { frequency } \\
(\mathrm{MHz})\end{array}$ & $\begin{array}{c}\text { Gain } \\
(\mathrm{dB})\end{array}$ & $\begin{array}{c}\text { Resonance } \\
\text { frequency } \\
(\mathrm{MHz})\end{array}$ & $\begin{array}{c}\text { Gain } \\
(\mathrm{dB})\end{array}$ \\
\hline 1 & 112 & 0.95 & 115 & 1.13 \\
\hline 2 & 360 & 3.80 & 380 & 4.32 \\
\hline 3 & 630 & 5.28 & 630 & 4.91 \\
\hline 4 & 880 & 7.13 & 884 & 6.03 \\
\hline
\end{tabular}

For the plasma antenna and metallic antenna of radius $1.8 \mathrm{~cm}$ and length $60 \mathrm{~cm}$, gains corresponding to the resonance frequencies are shown in the Table 3 . From the Table 3 it is clear that for both the antennas there are only two resonance frequencies are obtained in the range of $1 \mathrm{MHz}$ to $1 \mathrm{GHz}$. Theses resonance frequencies are same and the gain corresponding to them are also nearly same for both the antennas. Furthermore from radiation patterns for these antennas it is observed that radiation patterns are Omnidirectional at the lower frequencies while both the antennas get directive towards the higher frequencies.
Table 3. Resonance frequency and corresponding Gain for configuration of $1.8 \mathrm{~cm}$ and length $60 \mathrm{~cm}$

\begin{tabular}{|c|c|c|c|c|}
\hline \multirow{2}{*}{ S. No. } & \multicolumn{2}{|c|}{ Plasma antenna } & \multicolumn{2}{c|}{ Metallic antenna } \\
\cline { 2 - 5 } & $\begin{array}{c}\text { Resonance } \\
\text { frequency } \\
(\mathrm{MHz})\end{array}$ & $\begin{array}{c}\text { Gain } \\
(\mathrm{dB})\end{array}$ & $\begin{array}{c}\text { Resonance } \\
\text { frequency } \\
(\mathrm{MHz})\end{array}$ & $\begin{array}{c}\text { Gain } \\
(\mathrm{dB})\end{array}$ \\
\hline 1 & 220 & 2.43 & 220 & 2.46 \\
\hline 2 & 700 & 3.94 & 700 & 3.75 \\
\hline
\end{tabular}

From the above discussion it is observed, all the plasma antennas and metallic antennas have same antenna parameters. However the difference observed in the resonance frequencies and gain may arise due to the difference in the conductivity of the metal and plasma. Furthermore the effects on antenna parameters due to variation in length and radius of plasma column are also investigated. The results suggest that when length of plasma column changes from $120 \mathrm{~cm}$ to $60 \mathrm{~cm}$ the number resonance frequencies reduces from four to two. Now when radius of plasma column changes from $1.8 \mathrm{~cm}$ to $0.8 \mathrm{~cm}$ at constant length $120 \mathrm{~cm}$, it is observed that the number resonance frequencies are same but gain corresponding to resonance frequencies are slightly different for both the antennas.

\section{CONCLUSION}

The simulation study is conducted for different configurations of plasma antenna and metallic antenna. Antenna parameters of such plasma antennas and metallic antennas are investigated. Resonance frequencies and radiation patterns are quite similar for two plasma antennas of constant length $(l=120 \mathrm{~cm})$ of different radius $(r=1.8$ $\mathrm{cm}$ and $0.8 \mathrm{~cm})$. However the antenna parameters get changed when the length of plasma column $(l=120 \mathrm{~cm}$ and $60 \mathrm{~cm})$ changed at constant radius $(r=1.8 \mathrm{~cm})$. It is quite interesting that gain for all configurations of plasma antennas varies with respect to resonance frequencies and slightly different from the metallic antennas of similar configuration. For plasma antenna of radius $(r=1.8 \mathrm{~cm})$ and length $(l=$ $120 \mathrm{~cm}$ ) gain increases from $1.14 \mathrm{~dB}$ to $7.22 \mathrm{~dB}$, while for metallic antenna it increases from $1.78 \mathrm{~dB}$ to $5.79 \mathrm{~dB}$. For plasma antenna of radius $(r=0.8 \mathrm{~cm})$ and length $(l=120$ $\mathrm{cm})$ gain increases from $0.95 \mathrm{~dB}$ to $7.13 \mathrm{~dB}$ while for metallic antenna it increases from $1.13 \mathrm{~dB}$ to $6.03 \mathrm{~dB}$. For plasma antenna of radius $(r=1.8 \mathrm{~cm})$ and length $(l=60 \mathrm{~cm})$ gain increases from $2.43 \mathrm{~dB}$ to $3.94 \mathrm{~dB}$, while for metallic antenna it increases from $2.46 \mathrm{~dB}$ to $3.75 \mathrm{~dB}$. Gain and radiation pattern can be controlled by operating frequencies and length of plasma antenna. This papers shows, working of plasma antenna as antenna is significant and the parameters are also nearly same as the metallic antenna of same configuration.

\section{ACKNOWLEDGMENT}

Authors are thankful to the members of the Department of Physics, Dr. Harisingh Gour Central University for their help and support at every stage of research. 


\section{REFERENCES}

[1]. G. G. Borg, J. H. Harris, D. G. Miljak, and N. M. Martin, "Application of Plasma Columns to Radiofrequency Antennas," Applied Physics. Letter, vol. 74, pp. 3272-3274, May 1999.

[2]. G. G. Borg, J. H. Harris, N. M. Martin, D. Thorncraft, R. Milliken, D. G. Miljak, B. Kwan, T. Ng, and J. Kircher, "Plasmas as Antennas: Theory, Experiment and Applications," Physics of Plasmas, Vol. 7, pp. 2198-2202, July 2000.

[3]. I. Alexeff, T. Anderson, "Experimental and Theoretical Results with Plasma Antennas," IEEE Trans. Plasma. Sci., Vol. 34, No. 2, pp. 567-568, April 2006

[4]. P. Kumar, R. Kumar, "Monopole Plasma Antenna Parameters" Indian Journal of Pure and Applied Physics, in press.

[5]. R. Kumar, D. Bora, "Experimental Study of Parameters of a Plasma Antenna", Plasma Science and Technology, Vol.12, pp. 592-600, October 2010.

[6]. R. Kumar, D. Bora, "A Reconfigurable Plasma Antenna", Journal of Applied Physics 107, pp. 053303, 2010.

[7]. T. Anderson, I. Alexeff, E. Farsh, N. Karnam, E. P. Pradeep, N. R. Pulasani, J. Peck, "An Operating Intelligent Plasma Antenna", Published in Pulsed Power 16th IEEE International Conference, USA, pp 353-356. ,June 2007

[8]. F. F. Chen, "Introduction to Plasma Physics and Controlled Fusion", $2^{\text {nd }}$ Ed., Springer International Addition, pp. 80-90, 1974

[9]. J. D. Kraus, R. J. Marhefka, “Antennas for all applications” (Tata McGraw-Hill Edition, India), 3rd Edn., p. 11-30, 2003

\section{AUTHORS PROFILE}

Prince Kumar received the B. Sc. degree in Physics, Chemistry and Mathematics in 2010 and M. Sc. degree in Physics in 2013 from Dr. Harisingh Gour University Sagar, India. Currently he is doing his $\mathrm{PhD}$ degree in the same university. His expertise in plasma physics especially in plasma antenna.

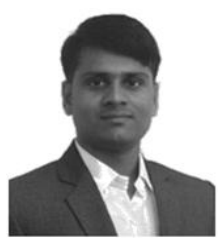

Rajneesh Kumar received the M. Sc. degree in Physics from Banaras Hindu University, Varanasi, UP. Later on he has completed his $\mathrm{PhD}$ degree from Institute of Plasma Research (IPR) Gandhinagar Gujarat India in Plasma Technology. He has worked for post-doctoral fellow at LAPLAC in France, MIST Abu Dhabi and IIT Kanpur. He has published four books

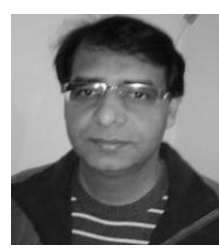
and one chapter on plasma technology. Former Assistant Professor in Department of Physics at Dr. Harisingh Gour Central University, Sagar, M.P. India. Recently he is working as an Associate Professor in Department of Physics at Banaras Hindu University, Varanasi, U.P. India. 